\title{
Design and analysis of full pitch winding and concentrated stator pole winding three-phase flux reversal machine for low speed application
}

\author{
D S MORE, HARI KALLURU and B G FERNANDES \\ Department of Electrical Engineering, Indian Institute of Technology Bombay, \\ Powai, Mumbai 400076 \\ e-mail: dsmore@ee.iitb.ac.in; khari@ee.iitb.ac.in; bgf@ee.iitb.ac.in
}

\begin{abstract}
The flux reversal machine (FRM) is a doubly-salient stator permanent magnet machine with flux linkage reversal in the stator concentrated winding. The existing machines at low speed, low power $(2.4 \mathrm{~kW}, 300 \mathrm{rpm})$ range are not economical. FRM topology is best suited for this application. An attempt has been made to improve the power density of machine by introducing full pitch winding. Full pitch winding FRM (FPFRM) has higher power density than the conventional concentrated stator pole winding FRM (CSPFRM).

Design and comparative analysis of FPFRM and CSPFRM are made. Both machines are designed for $88.58 \mathrm{Nm}$ and $300 \mathrm{rpm}$. Design details of both machines are presented. Finite Element Method (FEM) analysis is carried out to evaluate and compare the performance of CSPFRM and FPFRM. Series capacitive compensation is provided for better voltage regulation of both machines.
\end{abstract}

Keywords. Flux reversal machine (FRM); full pitch winding; doubly salient permanent magnet electrical machine; finite-element method (FEM) analysis.

\section{Introduction}

Single-phase FRM was first introduced by Deodhar et al (1997) for an automobile application to replace the standard claw pole alternator. It has numerous advantages such as simple construction, low inertia and high power density. Three-phase FRM was introduced by Wang et al (1999). The design of the machine has been optimized to ensure (i) high PM flux linkage in the winding, (ii) low cogging torque and permanent magnet (PM) weight. The basic machine configuration is an 8 salient pole rotor and 6 salient pole stator with concentrated windings. Permanent Magnets are fixed to the stator pole. Figure 1 shows this machine configuration.

FRM for low-speed servo drive application was introduced by Boldea et al (2002). This low speed machine has 28 poles on the rotor and 12 on stator with two permanent magnet pairs on each stator pole. This machine is designed for $128 \mathrm{rpm}$ at $60 \mathrm{~Hz}$. Using vector control high torque density with less than $3 \%$ torque pulsation is achieved. In order to reduce the cogging torque, rotor teeth pairing method has been proposed (Kim et al 2005). Attempts were made to reduce the leakage flux by providing flux barrier on the rotor poles at its edges 


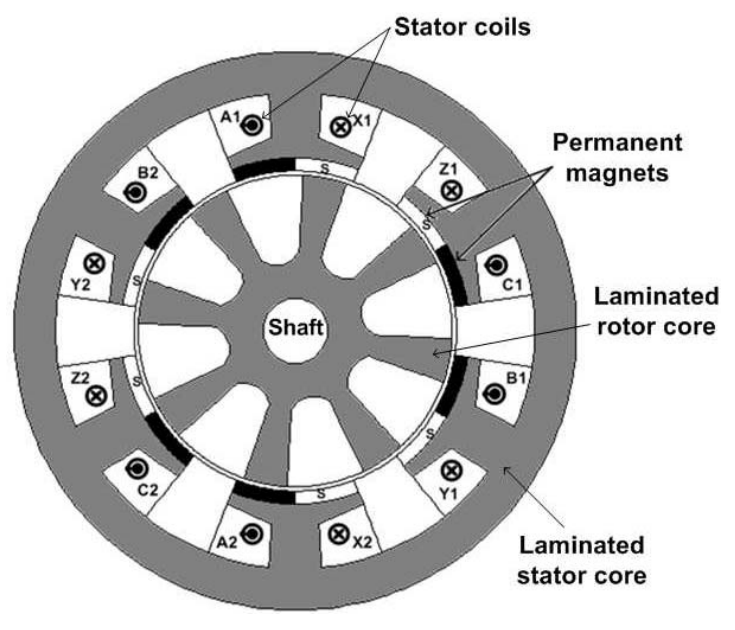

Figure 1. Cross-section of conventional 6/8 pole CSPFRM.

(Kim \& Lee 2004). Power density comparison of doubly salient permanent magnet machines has been made. It is concluded that FRM has higher power density in comparison with other machines in the same class (Zhang et al 2006).

The need for increased use of renewable energy is well established. Small-scale wind turbines (rooftop) have the potential to provide electricity to domestic and commercial applications. Rooftop wind energy generation has acquired importance due to environmental concerns. These generators should be direct driven. Since cogging torque can be reduced by proper skewing of the rotor, acoustic noise can be reduced. This is one of the requirement for rooftop wind generation system.

Depending upon the output power, the variation in the rated speed of the rooftop wind turbine is $140 \mathrm{rpm}$ to $500 \mathrm{rpm}$. Low capacity wind turbine has higher speed and as the capacity increases, the speed decreases. Rooftop wind power generation system has power rating variation from $0.6 \mathrm{~kW}$ to $15 \mathrm{~kW}$. The rated speed of $2.4 \mathrm{~kW}$ machine is $300 \mathrm{rpm}$. So, prototype of the machine $2.4 \mathrm{~kW}, 300 \mathrm{rpm}$ is designed.

In this paper, comparative analysis of low speed FPFRM and CSPFRM for the same power rating is made. FEM analysis using Flux 2D is carried out for both machines. Section 2 describes the basic operation of FRM. Full Pitch Winding FRM is discussed in $\S 3$. Section 4 describes the design details of CSPFRM and FPFRM for low speed application and the 2D FEM analysis for calculating the self and mutual inductance is discussed in $\S 5$. Section 6 describes the FEM analysis on load to determine the voltage regulation of both machines and a method used to improve the voltage regulation. Section 7 compares steady state motor performance of both machines and finally conclusions are drawn.

\section{Flux reversal machine}

The FRM is a doubly salient machine with permanent magnets on the stator. The PMs are fixed on the stator pole have opposite polarities and therefore as the rotor rotates PM flux linkage of the stator phase concentrated coils reverses the polarity under the same stator pole. Although the field excitation is provided by the permanent magnets, the flux linkage of the armature winding is modulated by the variation of the magnetic circuit reluctance as the rotor rotates in such a way that a bipolar EMF is induced without rotating magnets. Its simple 


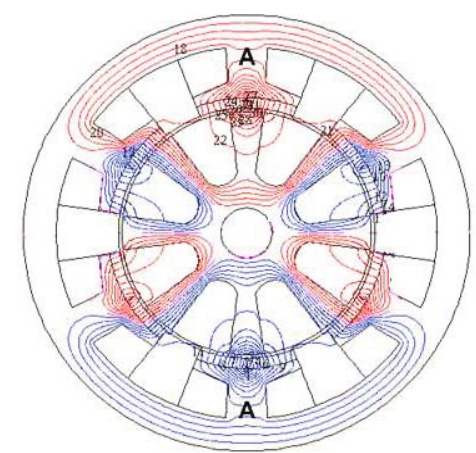

(a)

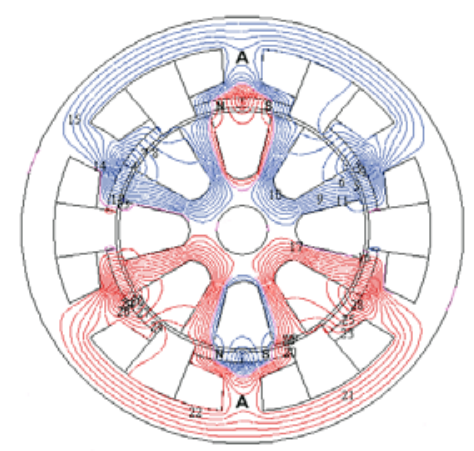

(c)

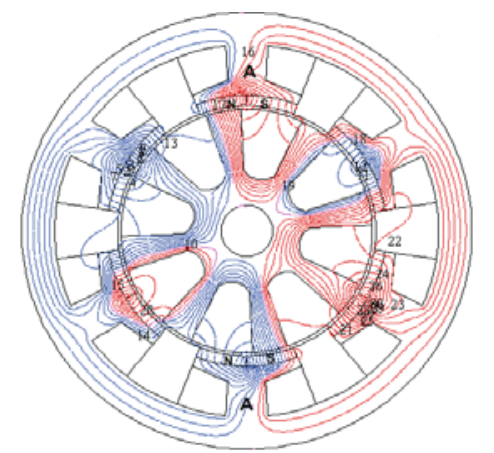

(b)

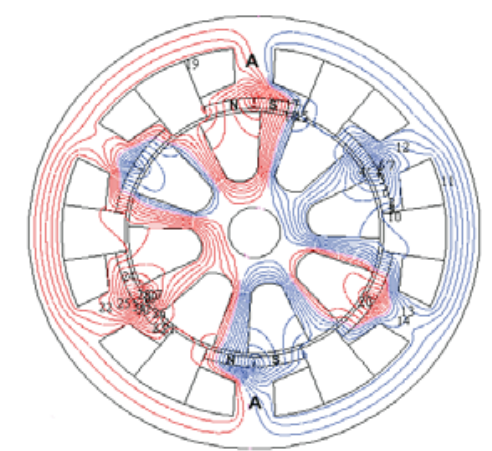

(d)

Figure 2. Operating principle of 6/8 pole FRM.

structure makes it cost effective and suitable for mass production. It has the advantages of switched reluctance machine (SRM) and permanent magnet synchronous machine (PMSM) (Deodhar et al 1997).

The principle of operation of 6/8 pole FRM is explained as follows: Figure 2a is an equilibrium position for A-phase, where the flux set-up by the magnets circulates entirely within A-phase stator pole, and there is no flux in the A-phase stator teeth. In this position no flux links with the A-phase coil. In figure $2 \mathrm{~b}$, the rotor is displaced by $11.25^{\circ}$ counter clockwise, so that the rotor pole aligns with one of the magnets. The flux now passes through the coils and the stator yoke. The flux linkage in A-phase is maximum at this position. In figure $2 \mathrm{c}$, the rotor is at a second equilibrium position, displaced from the first one by $22.5^{\circ}$, where, again, there is no flux in the A-phase stator teeth and no flux linking the A-phase coils. In figure $2 \mathrm{~d}$, rotor further displaced by $11.25^{\circ}$ in counter clockwise direction, where the phase flux is maximum in the direction opposite to the one shown in figure $2 \mathrm{~b}$. As the flux linking the stator winding is sinusoidal, the induced emf is also sinusoidal as shown in figure 3.

The frequency and speed relationship for FRM (Wang et al 1999) is given by

$$
f=\frac{N \times P_{r}}{60},
$$

where $N=$ rotor speed (rpm). 


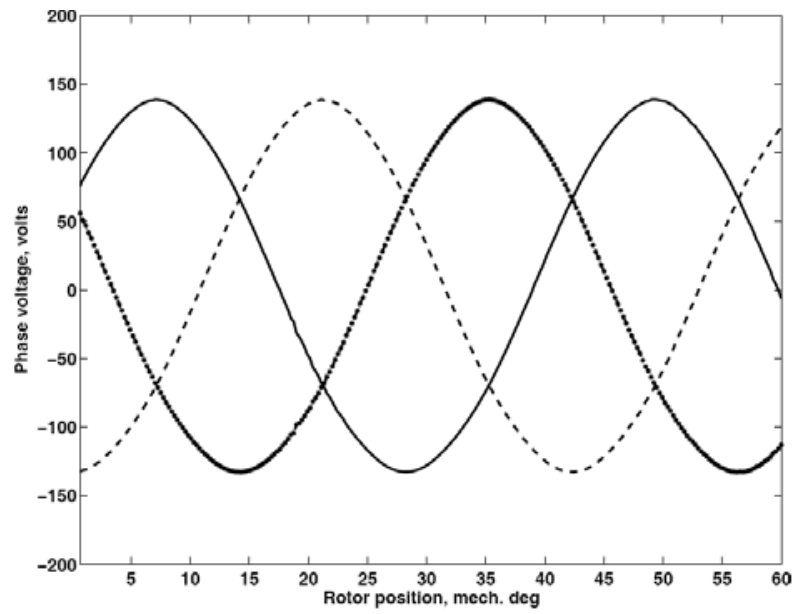

Figure 3. Induced EMF in $6 / 8$ pole FRM.

$P_{r}=$ number of rotor teeth or poles.

$f=$ frequency of induced $\operatorname{EMF}(\mathrm{Hz})$.

Where as number of equivalent flux pattern poles $\left(P_{e q}\right)$ is given by

$$
P_{e q}=P_{s} / 3
$$

where $P_{s}=$ number of stator poles.

FRM machine with $6 / 8$ pole has two effective poles, and hence in one cycle, flux pattern completes one revolution. Thus when rotor speed is $N$ rpm, the flux pattern completes $P_{r} \times N$ revolutions per minute. Hence, flux pattern rotates $P_{r}$ times the shaft speed. In conventional synchronous machine, flux pattern speed and rotor speed is same. Pictorial representation of FRM generator and permanent magnet synchronous generator is shown in figure 4. Both machine representation is for same speed and output frequency. Flux pattern in FRM rotating $P_{r}$ times rotor speed can be represented as a fictitious step-up gear and is called as 'Electrical Gear'. Electrical gear ratio (K) is defined as the ratio of flux pattern speed to the shaft speed. The value of $\mathrm{K}$ is given as

$$
K=\frac{P_{r}}{P_{e q} / 2} .
$$

Conventional synchronous machine should have $2 \times P_{r}$ poles for the same output frequency and rotor speed.

\section{Full pitch winding flux reversal machine}

Concept of fictitious 'Electrical Gear' in analysing the flux pattern in FRM and concept of full pitch winding for this machine was introduced. It was proved that full pitch winding increases the power density of the machine. Concept of fictitious electrical gear makes it possible to compare FRM with PMSM (More \& Fernandes 2007).

The normal component of flux density at the middle of stator pole along the periphery of $6 / 14$ pole FRM is shown in figure 5. The cross-section of 12/16 pole CSPFRM is given in figure 6. Machine configurations of 6/14 pole CSPFRM and FPFRM are shown in figures 7 


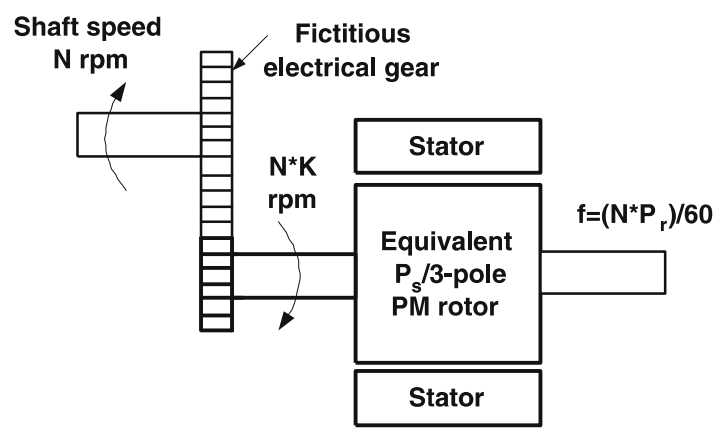

a) FRM

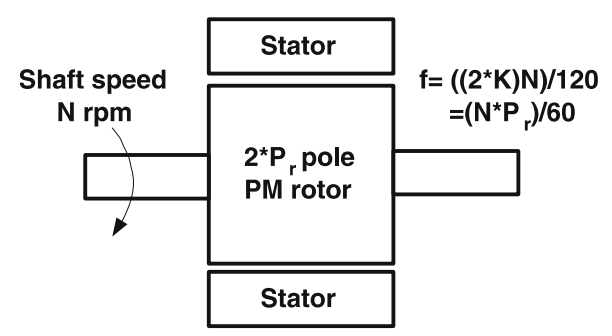

b) PMSM

Figure 4. Representation of fictitious electrical gear in FRM.

and 8 respectively. The close look on the normal component of flux density plot reveals that the machine has two pole flux pattern. In other words, the machine has two effective poles. FRM has 6 slots, hence electrical angle per slot is $60^{\circ}$. Concentrated stator pole winding has a coil span of $60^{\circ}$ elec. and therefore fundamental pitch factor of the (CSPFRM) stator winding is 0.5 . As electrical angle between the slots is $60^{\circ}$, full pitch winding is possible. The arrangement of full pitch winding is shown in figure 8 .

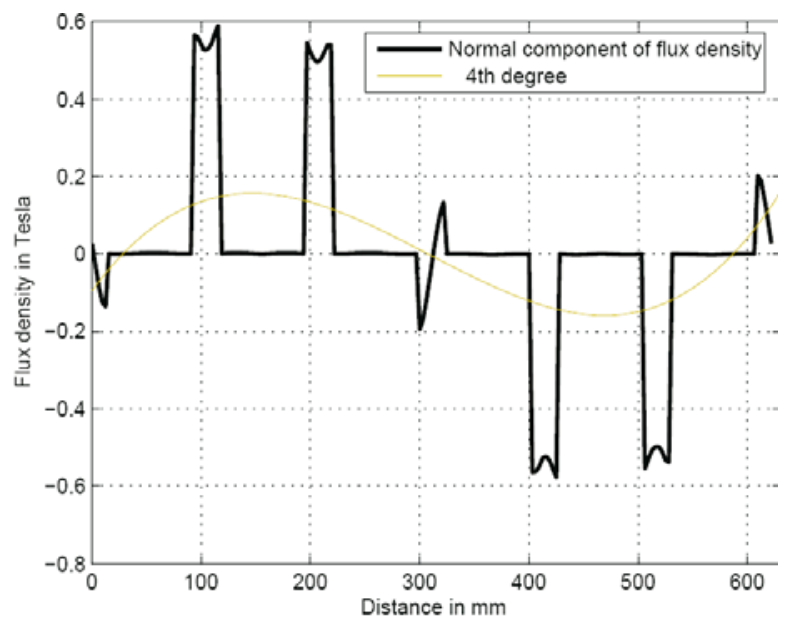

Figure 5. Normal component of flux density in 6/14 pole FRM. 

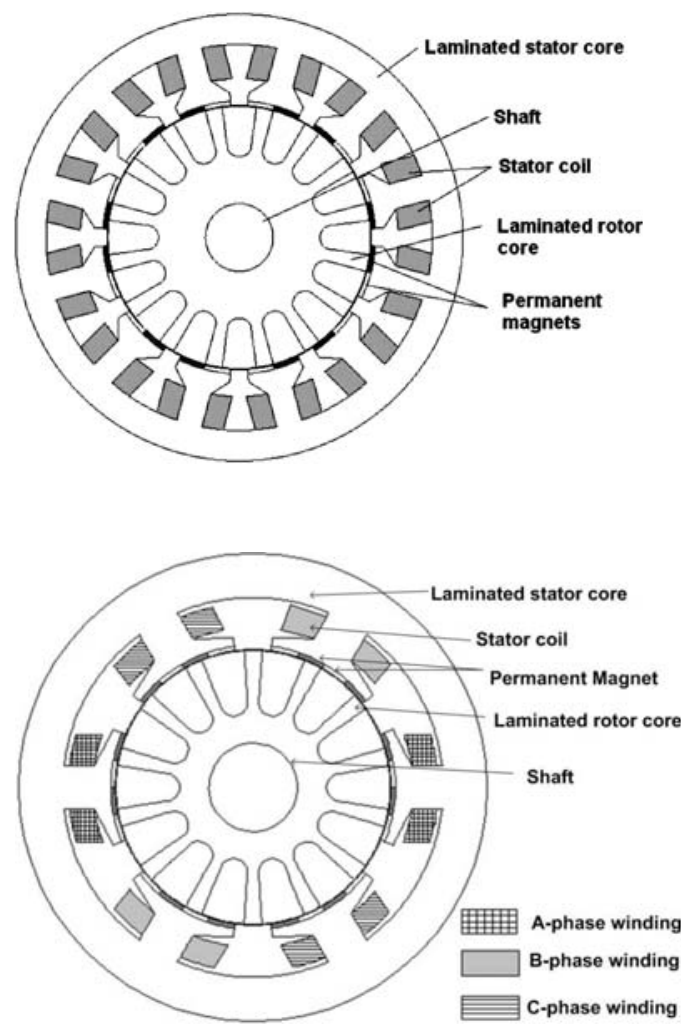

Figure 6. Cross-section of 12/16 pole CSPFRM.

Figure 7. Cross-section of $6 / 14$ pole CSPFRM.

Phase flux linkage variation of CSPFRM and FPFRM with the same physical dimensions and number of turns is shown in figure 9. The figure clearly shows that stator flux linkage in FPFRM is twice as that in CSPFRM. This results in high power density (More \& Fernandes 2007). Two machines are designed for the proof of this concept, one with full pitch winding arrangement and the other with concentrated stator pole winding. Both machines have identical power and speed rating.

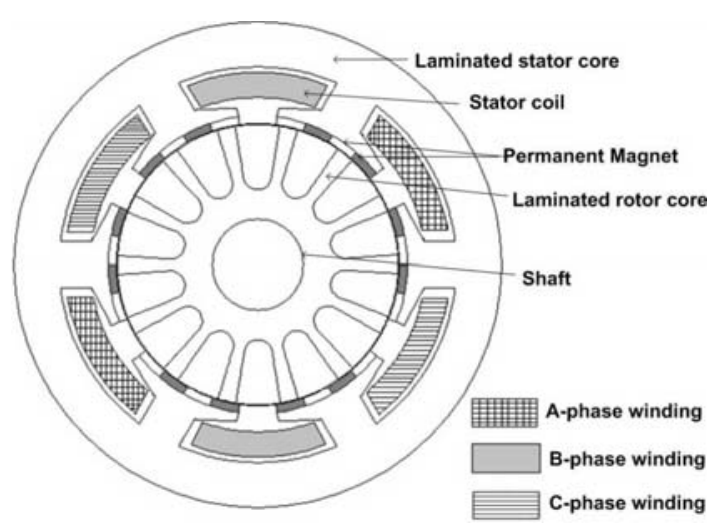

Figure 8. Cross-section of $6 / 14$ pole FPFRM. 


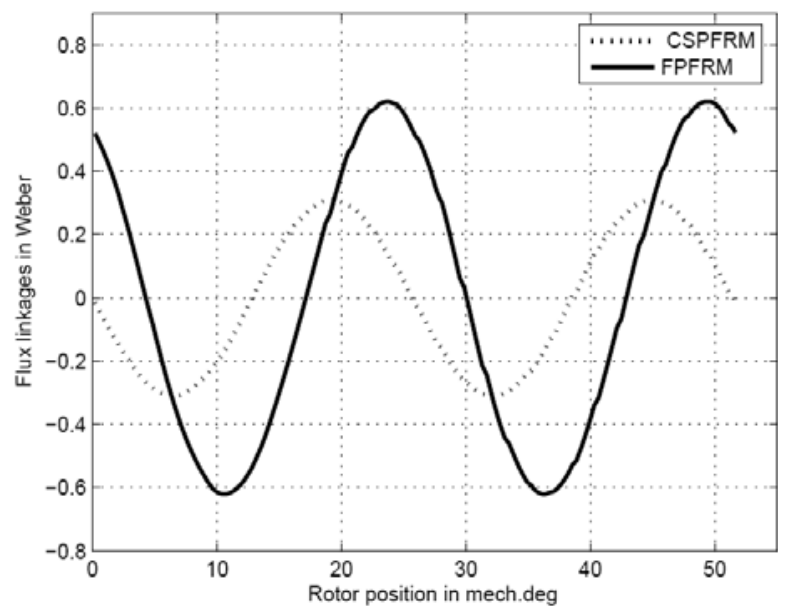

Figure 9. Phase flux Linkages in 6/14 pole CSPFRM and FPFRM.

\section{Design details of CSPFRM and FPFRM for low speed application}

FRM machine configurations suitable for $300 \mathrm{rpm}$ are:

- $12 / 16$ pole configuration.

- $6 / 14$ pole configuration.

The above configurations are shown in figures 6 and 7 respectively and their comparison is shown in table 1 . It is observed that $6 / 14$ pole configuration has effective flux pattern of 2 poles, where as 12/16 configuration has flux pattern of 4 poles as shown in figures 10 and 11 respectively. Stator flux linkage in $6 / 14$ pole configuration is twice as that of $12 / 16$ pole configuration for same magnet volume, physical dimensions and number of turns. Therefore $6 / 14$ pole configuration has higher power density than $12 / 16$ pole configuration. Hence, $6 / 14$ pole FRM configuration is selected. Detailed specifications of FRM is given in table 2.

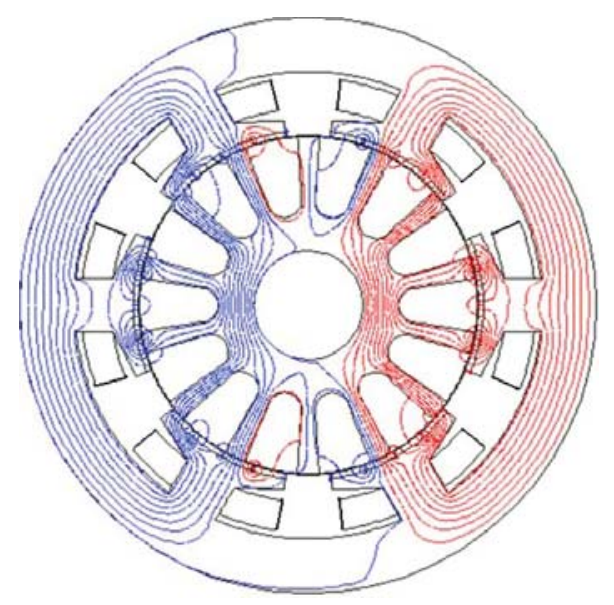

Figure 10. Flux pattern in 6/14 pole CSPFRM. 


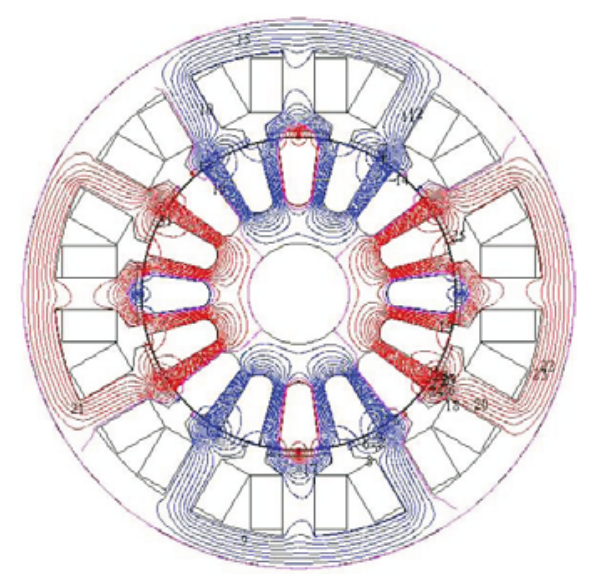

Figure 11. Flux pattern in 12/16 pole CSPFRM.

Table 1. Flux pattern poles for various FRM configurations.

\begin{tabular}{lcccc}
\hline Sr. No. & $\begin{array}{c}\text { Machine } \\
\text { type }\end{array}$ & $\begin{array}{c}\text { No. of } \\
\text { magnets }\end{array}$ & $\begin{array}{c}\text { Gear } \\
\text { ratio }\end{array}$ & $\begin{array}{c}\text { No. of Flux } \\
\text { pattern poles }\end{array}$ \\
\hline 1 & 6/8 pole & 12 & 8 & 2 \\
$\mathbf{2}$ & $\mathbf{1 2 / 1 6}$ pole & $\mathbf{2 4}$ & $\mathbf{8}$ & $\mathbf{4}$ \\
$\mathbf{3}$ & 6/14 pole & $\mathbf{2 4}$ & $\mathbf{1 4}$ & $\mathbf{2}$ \\
4 & 12/28 pole & 48 & 14 & 4 \\
5 & $12 / 40$ pole & 60 & 20 & 4 \\
\hline
\end{tabular}

\subsection{Sizing of FRM}

A procedure for sizing of FRM is given in Boldea et al (2002). Specific electrical and magnetic loading will determine the specific tangential force $f_{t}$. Relationship between machine dimensions and torque is given by

$$
T_{e}=f_{t} \pi D_{r} l_{s k} \frac{D_{r}}{2},
$$

Table 2. Specifications of 6/14 pole FRM.

\begin{tabular}{llcr}
\hline Sr. No. & \multicolumn{1}{c}{ Description } & Symbol & Value \\
\hline 1 & Torque of the machine (Nm) & $T_{e}$ & 89 \\
2 & Rated phase voltage (V) & $V_{p h}$ & 96 \\
3 & Rated speed (rpm) & $N$ & 300 \\
4 & Rated current (A) & $I$ & 10 \\
5 & Frequency (Hz) & $f$ & 70 \\
6 & Number of stator poles & $P_{s}$ & 6 \\
7 & Number of rotor poles & $P_{r}$ & 14 \\
8 & Number of magnet pairs & $n_{p p}$ & 2 \\
& $\quad$ per stator pole & & \\
\hline
\end{tabular}


where, $D_{r}=$ diameter of the rotor.

$l_{s k}=$ stack length of the machine.

The ratio of stack length to rotor diameter $\lambda$ is defined as

$$
\lambda=\frac{l_{s k}}{D_{r}} \text {. }
$$

From equations 4 and 5 the rotor diameter is given by

$$
D_{r}=\sqrt[3]{\frac{2 T_{e}}{\pi f_{t} \lambda}} .
$$

The PM flux per stator pole $\phi_{P M}$ is given by

$$
\phi_{P M}=l_{s k} \cdot B_{P M i} \cdot \tau_{P M} \cdot n_{p p} \cdot K_{\text {fringe }},
$$

where, $n_{p p}=$ number of magnet pairs per stator pole.

$K_{\text {fringe }}=$ ratio of flux linking the stator winding to airgap flux.

$\tau_{P M}=$ permanent magnet pole arc length.

The ideal flux density in the airgap $B_{P M i}$ is given by

$$
B_{P M i}=B_{r} \frac{h_{P M}}{h_{P M}+g},
$$

where, $B_{r}=$ remainent flux density of PM

$h_{P M}=$ permanent magnet thickness.

$g=$ airgap thickness.

FEM analysis shows that the variation of stator flux linkage is almost sinusoidal with rotor position $\theta_{r}$.

$$
\begin{aligned}
& \phi_{P M}\left(\theta_{r}\right)=\phi_{P M} \sin \left(P_{r} \theta_{r}\right) \\
& \frac{d \phi_{P M}\left(\theta_{r}\right)}{d \theta_{r}}=l_{s k} \cdot B_{P M i} \cdot \tau_{P M} \cdot n_{p p} \cdot K_{\text {fringe }} \cdot P_{r} \cdot \cos \left(P_{r} \theta_{r}\right) .
\end{aligned}
$$

There are $\frac{P_{s}}{3}$ stator poles per phase and $\frac{P_{s}}{3}$ coils in series with $n_{c}$ turns per coil. The EMF amplitude per phase is

$$
E_{m}=\frac{P_{s}}{3} \cdot n_{c} \cdot 2 \cdot \pi \cdot n \cdot l_{s k} \cdot B_{P M i} \cdot \tau_{P M} \cdot n_{p p} \cdot K_{\text {fringe }} \cdot P_{r} .
$$

The generalized equation applicable to three-phase flux reversal machines is given by

$$
E_{m}=\frac{P_{s}}{3} \cdot n_{c} \cdot 2 \cdot \pi \cdot n l_{s k} \cdot B_{P M i} \cdot \tau_{P M} \cdot K_{\text {fringe }} \cdot n_{p p} \cdot P_{r} \cdot K_{w t},
$$

where, $K_{w t}$ is winding type factor that depends upon the type of winding in FRM (i.e. concentrated stator pole winding and full pitch winding). Value of $K_{w t}$ for both windings is shown in table 3.

In constant torque region, FRM is controlled by maintaining $I_{d}=0$. The rated phase current of the machine is given by

$$
I=\frac{2 \pi n T_{e}}{\frac{3 E_{m}}{\sqrt{2}}} .
$$


Table 3. Value of $K_{w t}$ for different types of FRM winding.

\begin{tabular}{llc}
\hline Sr. No. & \multicolumn{1}{c}{ Description } & Value \\
\hline 1 & Concentrated stator pole winding & $1 \cdot 0$ \\
2 & Full pitch winding & $2 \cdot 0$ \\
\hline
\end{tabular}

Having determined the number of turns per coil and phase current, the slot area required for the winding is obtained by considering the slot fill factor $\left(K_{\text {fill }}\right)$ and winding current density $\left(j_{c n}\right)$. The slot area is given by

$$
A_{\text {slot }}=\frac{2 n_{c} I}{j_{c n} K_{f i l l}} .
$$

Stator pole width is decided based on magnet width $\tau_{P M}$ and flux density in stator pole. Stator slot area determines the stator pole height. Stator core width is taken to be equal to stator pole width, and stator pole arc to pole pitch ratio is taken as 0.75 for $6 / 14$ pole CSPFRM (Wang et al 1999). Two magnet pole pairs per stator pole are used. The rotor pole span is taken as $120^{\circ}$ electrical and the airgap between stator and rotor is $0.5 \mathrm{~mm}$. Magnet thickness is $2.5 \mathrm{~mm}$.

\subsection{Dimensions of CSPFRM}

The main dimensions of $6 / 14$ pole, $2.4 \mathrm{~kW}(88.58 \mathrm{Nm})$ CSPFRM are determined using the procedure given above. Following data is assumed for the design of the machine.

- Specific force $f_{t}=1.6 \mathrm{~N} / \mathrm{cm}^{2}$

- $\lambda \approx 1 \cdot 0$

- Efficiency of the machine $=86 \%$

- PM remnant flux density $B_{r}=1.2$ Tesla

- Flux leakage factor $K_{\text {fringe }}=0.44$

- Slot fill factor $K_{\text {fill }}=0 \cdot 3$

- Winding current density $j_{c n}=3.5 \mathrm{Amps} / \mathrm{mm}^{2}$.

The dimensions of $6 / 14$ pole, $88.58 \mathrm{Nm}, 300 \mathrm{rpm}$ CSPFRM is given in table 4 . The overall dimensions of the machine are shown in the figure $12 \mathrm{a}$.

\subsection{Dimensions of FPFRM}

Design equations for CSPFRM and FPFRM are same except the voltage per turn. Voltage induced in FPFRM is twice as that in CSPFRM for same magnetic and electrical loading. In order to reduce the material and manufacturing cost, physical dimensions (cross section and number of turns) of both machines are taken to be the same except the stack length. For the same physical dimensions and power, the stack length of FPFRM is ideally half of that of CSPFRM. However the FPFRM has higher voltage regulation due to higher value of inductance. In order to obtain same torque (power output), stack length of FPFRM is increased by $13 \%$ of its ideal length. This stack length is $56.6 \%$ of CSPFRM. Thus the stack length of FPFRM is $85 \mathrm{~mm}$. The overall dimensions of the machine are shown in the figure $12 \mathrm{~b}$. 
Table 4. Dimensions of $6 / 14$ pole, 88.58 Nm, 300 rpm CSPFRM.

\begin{tabular}{llcc}
\hline Sr. No. & \multicolumn{1}{c}{ Description } & Symbol & Value \\
\hline 1 & Airgap (mm) & $\mathrm{g}$ & $0 \cdot 5$ \\
2 & Magnet thickness (mm) & $h_{p m}$ & $2 \cdot 5$ \\
3 & Rotor pole span angle ( ${ }^{\circ}$ mech.) & $\beta_{r}$ & $7 \cdot 5^{\circ}$ \\
4 & Stator pole span angle ( ${ }^{\circ}$ mech.) & $\beta_{s}$ & $45^{\circ}$ \\
5 & Stator pole span (mm) & $\tau_{p s}$ & $63 \cdot 2$ \\
6 & Rotor pole span (mm) & $\tau_{p r}$ & $10 \cdot 2$ \\
7 & Stator pole height (mm) & $h_{p s}$ & 27 \\
8 & Rotor pole height (mm) & $h_{p r}$ & 30 \\
9 & Outer diameter of rotor (mm) & $D_{i}$ & 155 \\
10 & Outer diameter of stator (mm) & $D_{o}$ & 264 \\
11 & Number of turns/phase & $N_{p h}$ & 132 \\
12 & Stack length of machine (mm) & $l_{s k}$ & 150 \\
13 & Stator pole width (mm) & $W_{s p}$ & 25 \\
14 & Stator core width (mm) & $W_{s c}$ & 25 \\
15 & Shaft diameter (mm) & $D_{s h}$ & 50 \\
\hline
\end{tabular}

\subsection{Iron Loss of CSPFRM and FPFRM}

FEM analysis is used to determine the flux density and frequency of the flux reversal in each part of the machine. Cold rolled non grain oriented silicon steel lamination (CRNGO) of $0.5 \mathrm{~mm}$ thick M-36 grade is used for constructing the machine. Specific iron loss for each part of the machine is decided based on flux density and frequency of flux reversal. Table 5 shows the iron loss in each part of CSPFRM calculated from specific iron loss and weight of laminations. The calculated total iron loss is $59 \mathrm{~W}$ and total weight of laminations is $39 \mathrm{Kg}$.

Stack length of CSPFRM and FPFRM is $150 \mathrm{~mm}$ and $85 \mathrm{~mm}$ respectively. The core loss in FPFRM is $33.50 \mathrm{~W}$ and weight of the core is $22 \cdot 15 \mathrm{Kg}$.

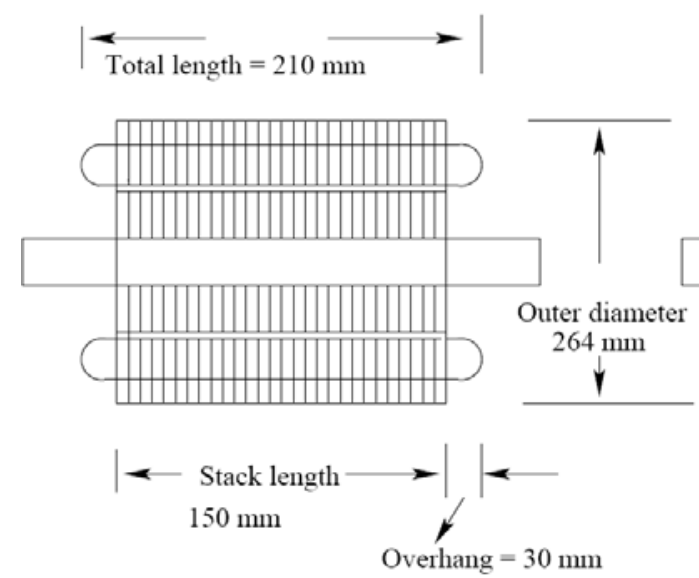

(a) CSPFRM

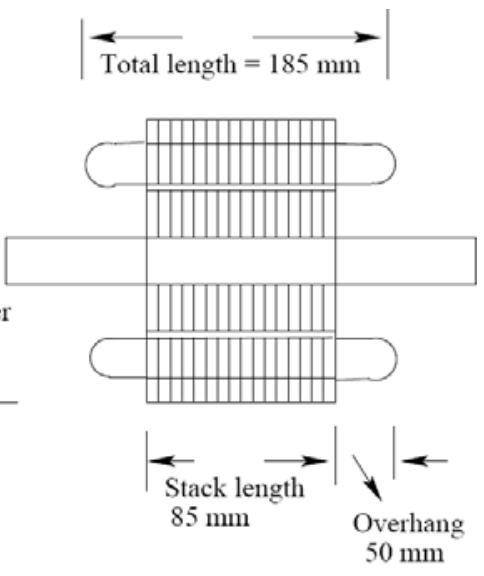

(b) FPFRM

Figure 12. Overall dimensions of CSPFRM and FPFRM. 
Table 5. Iron loss of 6/14 pole CSPFRM.

\begin{tabular}{llcccrc}
\hline Sr. No. & $\begin{array}{c}\text { Machine } \\
\text { part }\end{array}$ & $\begin{array}{c}\text { flux } \\
\text { density } \\
\text { Wb/m }\end{array}$ & $\begin{array}{c}\text { Frequency } \\
\mathrm{Hz}\end{array}$ & $\begin{array}{c}\text { Specific } \\
\text { loss } \\
\text { W/Kg }\end{array}$ & $\begin{array}{c}\text { Weight } \\
\text { Kg. }\end{array}$ & $\begin{array}{c}\text { Iron } \\
\text { loss } \\
\text { Watts }\end{array}$ \\
\hline 1 & Rotor core & 0.8 & 65 & 1.79 & 5.88 & 10.5 \\
2 & Rotor pole & 0.8 & 65 & 1.79 & 4.93 & 8.82 \\
3 & Stator core & 0.6 & 70 & 1.17 & 21.53 & 25.19 \\
4 & Stator pole & 0.6 & 70 & 1.17 & 2.92 & 3.416 \\
5 & Stator pole shoe & 1.0 & 70 & 2.98 & 3.75 & 11.175 \\
\hline
\end{tabular}

\subsection{Winding Resistance and Copper Loss of FPFRM and CSPFRM}

Number of turns and cross-section of the conductor is same in both the machines. However stack length and end turn overhang are different. Overhang of FPFRM is higher, which results in higher resistance and copper loss. The details of winding resistance, copper loss and copper weight for both machines are given in table 6 .

\section{Self and mutual inductance of CSPFRM and FPFRM}

Self and mutual inductances are calculated using FEM analysis. Variation of self inductance of 6/14 pole CSPFRM and FPFRM with rotor position is shown in figure 13. It is observed that the ratio of self inductance of FPFRM to CSPFRM is 1.6.

The variation of mutual inductance between the phases of FPFRM and CSPFRM is shown in figure 14. The mutual inductance between the phases of CSPFRM is very low (i.e. $0.44 \mathrm{mH}$ to $0.56 \mathrm{mH}$ ). This inductance between the phases of FPFRM varies with rotor position. These values for both machines obtained from FEM are shown in table 7.

\section{Voltage regulation of the machine}

Voltage regulation of FPFRM and CSPFRM generator for resistive load are obtained at $300 \mathrm{rpm}$ with FEM simulation. The no load voltages of CSPFRM and FPFRM are 96.76 volt and 109.8 volt respectively. Figure 15 shows the variation of terminal voltage with load of both machines. The regulation of both machines is poor due to armature reaction. Series capacitive compensation is provided for both machines to improve the voltage regulation. The

Table 6. Winding data of 6/14 pole CSPFRM and FPFRM.

\begin{tabular}{llcc}
\hline Sr. No. & Parameter & CSPFRM & FPFRM \\
\hline 1 & Winding resistance & 0.3928 & 0.6363 \\
& per phase (Ohm) & & \\
2 & Copper loss (Watt) & 120.00 & $195 \cdot 50$ \\
3 & Copper weight (Kg) & $5 \cdot 1498$ & $8 \cdot 29$ \\
4 & Magnet weight (Kg) & 1.10 & 0.623 \\
\hline
\end{tabular}




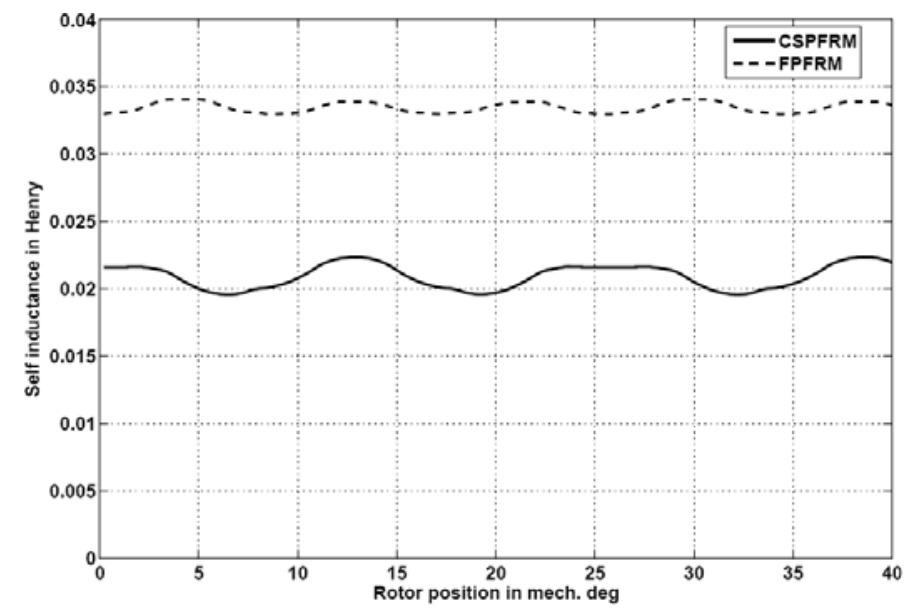

Figure 13. Variation of self inductance with rotor position for 6/14 pole CSPFRM and FPFRM.

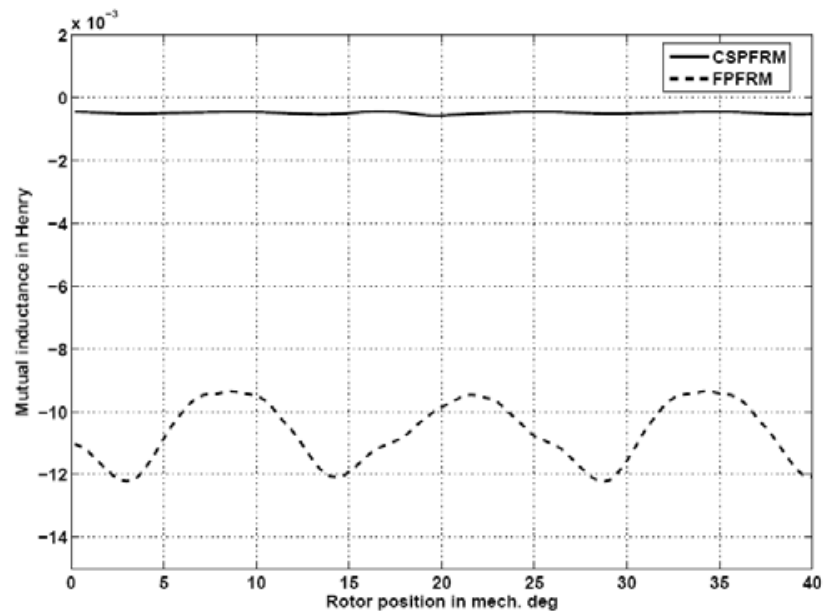

Figure 14. Variation of mutual inductance with rotor position for 6/14 pole CSPFRM and FPFRM.

Table 7. Self and mutual inductance of 6/14 pole CSPFRM and FPFRM.

\begin{tabular}{lccr}
\hline Sr. No. & Parameter & CSPFRM & FPFRM \\
\hline 1 & $\begin{array}{c}\text { Self inductance with FEM } \\
\text { analysis (min. value) in mH } \\
\text { Self inductance with FEM } \\
\text { analysis (max. value) in mH } \\
\text { Mutual inductance with FEM } \\
\text { analysis (min. value) in mH }\end{array}$ & 19.57 & 32.96 \\
3 & $\begin{array}{c}\text { Mutual inductance with FEM } \\
\text { analysis (max. value) in mH }\end{array}$ & 0.54 & 34.07 \\
4 & & 9.35 \\
\hline
\end{tabular}




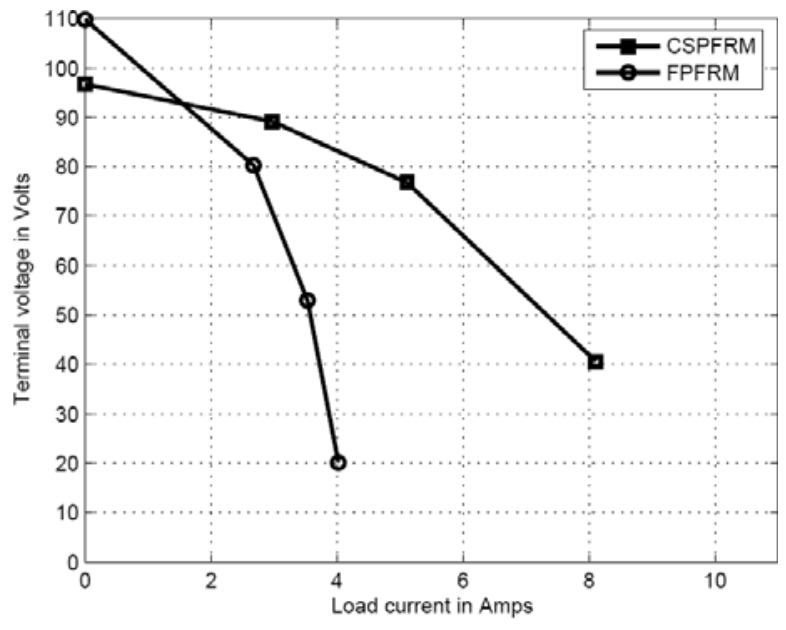

Figure 15. Voltage regulation characteristics of $6 / 14$ pole CSPFRM and FPFRM.

uncompensated regulation characteristic is used to calculate the value of synchronous inductance $L_{s}$, which is used to determine the size of capacitor for series capacitive compensation of the machine.

Voltage regulation of FPFRM and CSPFRM is improved with series capacitive compensation. The value of series capacitance is given by Naoe (1997); Wang et al (2001).

$$
C=\frac{1}{\omega^{2} \times L_{s}},
$$

where $\omega=$ output frequency of voltage ( $\mathrm{rad} / \mathrm{sec})$.

$L_{s}=$ synchronous inductance of the machine/phase $(\mathrm{H})$.

The regulation characteristics for compensated CSPFRM and FPFRM are shown in figure 16.

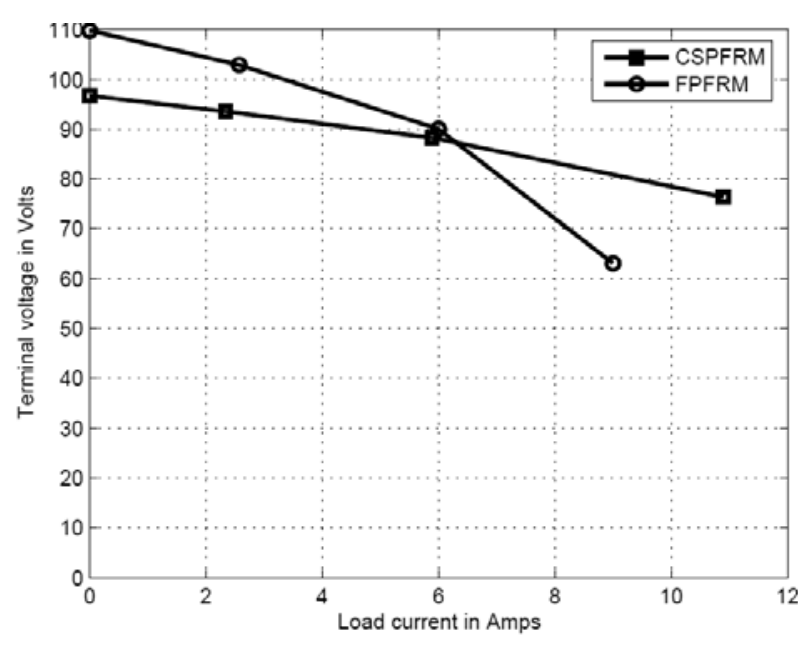

Figure 16. Variation of voltage regulation with load for $6 / 14$ pole compensated CSPFRM and FPFRM. 


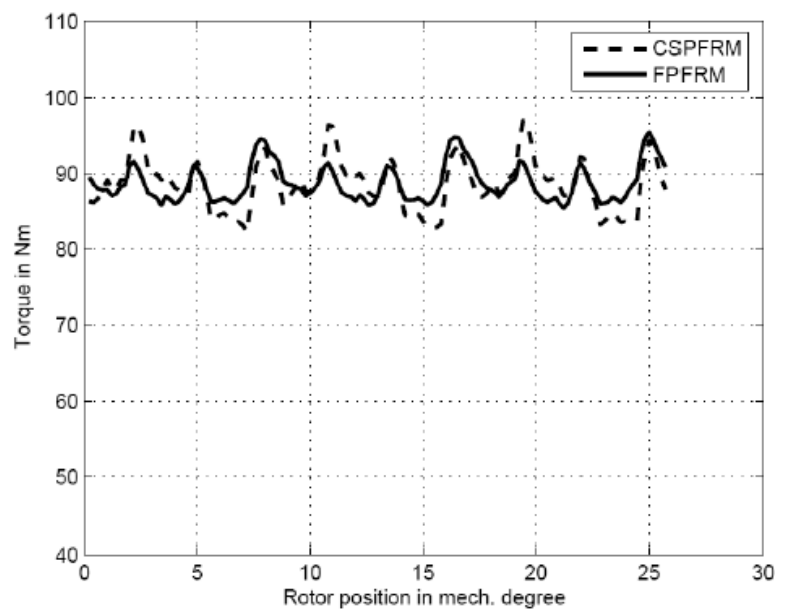

Figure 17. Steady state torque of $6 / 14$ pole CSPFRM and FPFRM at rated current.

The values of compensating capacitors for CSPFRM and FPFRM are $195 \mu \mathrm{F}$ and $85.66 \mu \mathrm{F}$ respectively.

\section{Steady state motor performance of FPFRM and CSPFRM}

FEM simulation is carried out on both machines to determine the developed torque at rated current. At rated speed, the torque produced by the machine is obtained by aligning the stator current along q-axis (i.e. $I_{d}=0$ ) (Gieras \& Wing (2002), Miller (1989).

The variation of steady state torque produced by both machines with rotor position is shown in figure 17. The minimum and maximum values of torque for CSPFRM are $82 \mathrm{Nm}$ and $97.2 \mathrm{Nm}$ respectively. These values for FPFRM are $85.44 \mathrm{Nm}$ and $95.44 \mathrm{Nm}$ respectively. The average value of torque for CSPFRM is $88.57 \mathrm{Nm}$ and FPFRM is $88.74 \mathrm{Nm}$.

Voltage required to drive the motor at rated current are different for both machines. The rms AC voltages required for CSPFRM and FPFRM are 138 volts and 226 volts respectively. The waveforms of voltages required to supply sinusoidal current into the machine is shown in

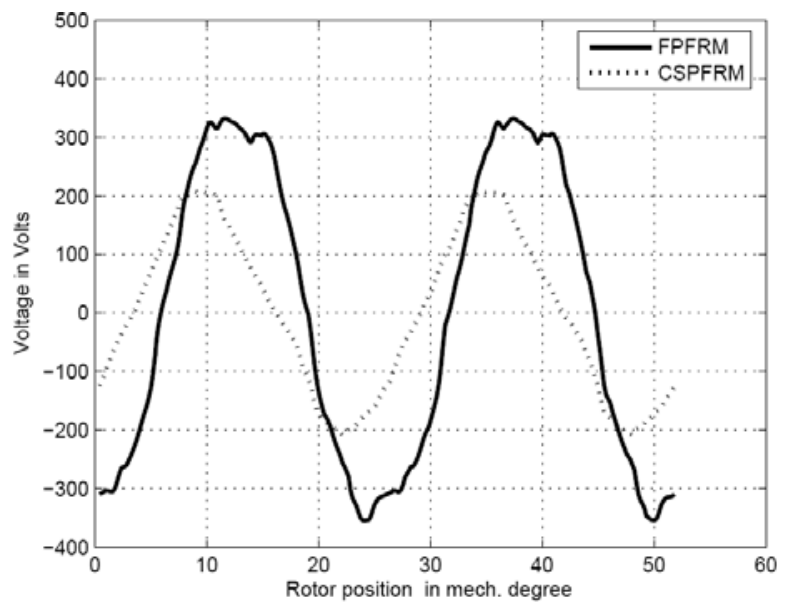

Figure 18. Phase voltage waveforms of 6/14 pole CSPFRM and FPFRM at rated current. 
Table 8. Comparison of motor performance of 6/14 pole CSPFRM and FPFRM.

\begin{tabular}{llrr}
\hline Sr. No. & \multicolumn{1}{c}{ Parameter } & CSPFRM & FPFRM \\
\hline 1 & Phase voltage $(\mathrm{V})$ & 138.00 & 226.00 \\
2 & Torque $(\mathrm{Nm})$ & 89.00 & 89.00 \\
3 & Active weight of the machine $(\mathrm{Kg})$ & 45.30 & 31.00 \\
4 & Torque to weight ratio $(\mathrm{Nm} / \mathrm{Kg})$ & 1.96 & 2.87 \\
\hline
\end{tabular}

figure 18. Comparison of both machines is given in table 8. From this table it can be inferred that torque to weight ratio of FPFRM is 1.46 times the CSPFRM. The cost of FPFRM is less as material cost is less. Thus FPFRM is low cost, high power density machine as compared to CSPFRM.

\section{Conclusion}

The design details of CSPFRM and FPFRM are presented. FEM analysis is carried out to evaluate the performance of these machines. Self inductance of FPFRM is approximately 1.6 times that of CSPFRM which resulted in poor voltage regulation. Series capacitive compensation is provided to improve the voltage regulation. Motor performance of both machines is evaluated with FEM and it showed that the torque produced by both machines are approximately equal. Torque to weight ratio of FPFRM is 1.46 times higher than CSPFRM and cost of FPFRM is less as material cost is less. Hence it could be concluded that FPFRM is a low cost, high power density machine as compared to CSPFRM.

\section{References}

Boldea Ion, Zhang Jichum, Nasar S A 2002 Theoretical characterization of flux reversal machine in low speed servo drives-The pole PM configuration. IEEE Trans. Industry Applications 38(6) $1549-1557$

Deodhar R P, Anderson Savante, Boldea Ion, Miller T J E 1997 The flux reversal machine: A new doubly salient permanent magnet machine. IEEE Trans. Industry Applications 33(4): 925-934

Gieras J F, Wing M 2002 Permanent Magnet Motor Technology Design and Applications. Marcel Dekker Inc.

Kim Tae Heoung, Lee Ju 2004 A study of the design for the flux reversal machine. IEEE Trans. on Magnetics. 40(4): 2053-2055

Kim Tae Heoung, Sung Hong Won, Ki Bong, Ju Lee 2005 Reduction in cogging torque in flux reversal machine by rotor teeth pairing. IEEE Trans. on Magnetics 41(10): 3964-3966

Miller T JE 1989 Brushless permanent magnet and reluctance motor drives. (Oxford: Clarendon Press)

More D S, Fernandes B G 2007 Novel three phase flux reversal machine with full pitch winding. Proc. of International Conference on Power Electronics (ICPE 2007) Daegu, South Korea 1007-1012

Naoe Nobuyuki 1997 Voltage compensation of permanent Magnet generator with capacitors. Proc.

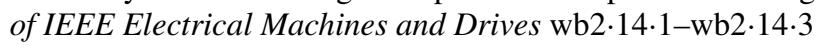

Wang C, Nasar S A, Boldea I 1999 Three phase flux reversal machine (FRM). IEE Trans. Electrical Power Application 146(2) 139-146

Wang C, Boldea I, Nasar S A 2001 Characterization of three-phase flux reversal machine as an automotive generator. IEEE Trans. on Energy Conversion 16(1): 74-80 
Zhang Jianzhong, Cheng Ming, Hua Wei, Zhu Xiaoyong 2006 New approach to power equation for comparison of doubly salient electrical machines. Proc. IEEE Industry Applications Annual. Meeting 1178-1185

CEDRAT France Flux 2D FEM Software (www.cedrat.com) 